\title{
Spatial distribution of horizontal seismic strain in the Apennines from historical earthquakes
}

\author{
Giulio Selvaggi \\ Istituto Nazionale di Geofisica, Roma, Italy
}

\begin{abstract}
Horizontal principal seismic strain rate axes have been calculated within a regular mesh of triangles covering the Italian peninsula in a time interval of 700 years. I have used both the method of Kostrov (1974), that requires knowledge of the seismic moment tensor of earthquakes, and the modified version provided by England and Molnar (1997) that makes use of length and kinematics of the activated faults. Seismic moment tensor of historical earthquakes can be inferred from recent literature, while length of faults has been obtained from the observation that strain drop is almost constant for large Apenninic earthquakes. Spatial strain distribution from historical earthquakes shows that the Apennines can be divided into three homogeneous structural arcs (Northern Apenninic, Southern Apenninic and Calabrian arcs) within which strain is roughly constant. Although NESW extension is the main deformation process along the two Apenninic arcs it involves a velocity more than five times greater in the Southern Apennines. Along the Calabrian arc, I tested the effect on the strain field of the contemporaneous WNW-ESE and $\sim$ NNE-SSW extension due to the longitudinal dilatation of the arc
during its still ESE migration.
\end{abstract}

Key words seismic strain rate - extension rate Apennines

\section{Introduction}

Within a still active $\sim$ NS convergence of Africa towards Eurasia, extensional processes dominate the style of deformation of the Western Mediterranean (fig. 1). These processes, mainly related to subduction, have led, since the Tertiary, to the opening of Alboran, Liguro-Provençal, and Tyrrenian extensional basins, which are surrounded by orogens (e.g., Betic-Rif arc or Apenninic arc). Seismic deformation is not distributed in these deforming re-

Mailing address: Dr. Giulio Selvaggi, Istituto Nazionale di Geofisica, Via di Vigna Murata 605, 00143 Roma, Italy; e-mail: selvaggi@marte.ingrm.it gions but rather it concentrates in narrow bands located in or in the proximity of mountain belts. Fault plane solutions of large earthquakes occurring along the Apennines indicate that seismic deformation tends to accommodate the extension (Jackson and Mckenzie, 1988; Jackson et al., 1992). The goal of this work is to provide a quantitative analysis of seismic deformation along the Italian peninsula to see to what extent extensional processes are still dominating. There are several reasons why it is desirable to have the spatial distribution of seismic strain. First, dynamic models proposed in past years would greatly benefit from a kinematic description derived from seismic data, and secondly, comparison between forthcoming geodetic strain measurements and seismic strain will reveal how much of the deformation is achieved aseismically. For the time being, due to the insufficient sampling of geodetic data, the shape of the average strain 




Fig. 1. Schematic picture of the Mediterranean region. The black arrow indicates the current motion of Africa relative to Eurasia, while white arrows show the extensional basins opened since the Tertiary and the direction of extension. Arrow lengths are only indicative. Dots are earthquakes located in the past 5 years and reported in the NEIC catalogue.

rate tensor derived from geodesy is not consistent with the average seismic strain rate tensor calculated from earthquakes. This suggests that the seismic deformation is driven by small scale tectonic processes not yet seen by geodesy and that a more dense sampling of geodetic data is needed before the comparison between geodetic and seismic strain can be established. This latter point represents a compelling step for a modern evaluation of seismic hazard of an active region.

A complete kinematic description should take into account both relative velocities and rotations, that define the velocity gradient tensor $\boldsymbol{L}$ (Jackson and Mckenzie, 1988). The velocity gradient tensor is the sum of the symmetric tensor $S$, the strain rate tensor, and the antisymmetric tensor $\boldsymbol{A}$, corresponding to a rigid body rotation (Jackson and Mckenzie, 1988). Haines (1982) showed that if rates of horizontal shear strain are everywhere known, the horizontal velocity field and rotations can be recovered. The complete horizontal motion retrieved from seismic strain rate data will be treated in a forthcoming paper. In this paper I have computed a more detailed map of crustal seismic strain along the Apennines and for a longer time interval ( 7 centuries) with respect to previous papers (Anderson and Jackson, 1987; Jackson and McKenzie, 1988; Westaway 1992; Pondrelli et al., 1995), in the conviction that in low seismic strain rate regions only a large time window provides strain estimates meaningful for tectonics interpretation.

Average strain rate tensor can be retrieved from summation of moment tensors within a volume following Kostrov's (1974) approach:

$$
\dot{\bar{\varepsilon}}_{i j}=\frac{1}{2 \mu V t} \sum_{k=1}^{N} M_{o}^{k} m_{i j}^{k} .
$$


where $\mu$ is the shear modules, $V$ is the volume, $t$ is the time interval, and $M_{o}^{k} m_{i j}^{k}$ is the moment tensor of the $k$ earthquake with scalar seismic moment $M_{o}^{k}$. Recently, England and Molnar (1997) showed that average strain rate tensor can be equally defined in terms of moment tensor and length of faults averaged in a mesh of triangles covering a region

$$
\dot{\bar{\varepsilon}}_{i j}=\frac{1}{2 \Delta} \sum_{k=1}^{N} L^{k}\left(\frac{u_{i}^{k} n_{j}^{k}+u_{j}^{k} n_{i}^{k}}{\sin \delta^{k}}\right)
$$

where $\Delta$ is the triangle area, $L$ is the length of faults, $\delta$ is the dip of the fault, $u$ and $n$ are the component of the slip rate and the normal to the faults, respectively. The data needed for relation (1.1) are basically moment rate tensor of earthquakes, while (1.2) needs the additional information of the knowledge of fault length. I followed both the approach for the computation of strain of Apennines, showing that the formula provided in England and Molnar (1997) better averages the spatial distribution of strain, treating faults with finite dimension and not like point source, thus shearing strain from faults belonging to adjacent triangles.

Within Italy, seismic deformation is concentrated in a narrow belt running along the Apennines (Cocco et al., 1993; Selvaggi et al., 1997). This belt is everywhere $30-40 \mathrm{~km}$ wide with the exception of the transition zone between Northern and Southern Apennines where it widens to about $100 \mathrm{~km}$ (Selvaggi et al., 1997). Large earthquakes occur in this seismic belt with decades of time interval, clearly showing NE-SW extension in the Apennines and ESE-WNW extension in the Calabrian arc.

The average extension rate in the Apennines ranges between 1 and $3 \mathrm{~mm} / \mathrm{yr}$ calculated in a relative short time interval of 16 to 85 years of seismicity (Anderson and Jackson, 1987; Jackson and McKenzie, 1988; Pondrelli et al., 1995). Westaway (1992) found an extension rate of more than one order of magnitude greater in Southern Apennines (up to $\approx 5 \mathrm{~mm} / \mathrm{yr}$ ) with respect to Northern Apennines $(\approx 0.3 \mathrm{~mm} / \mathrm{yr})$ considering nearly 400 years time interval from seismic moment of historical earthquakes estimated by macroseismic data. The open question that will be focused in the discussion refers to the evidence provided by Westaway (1992) that strain is not homogeneously distributed along the chain but rather it concentrates in the central part of the Southern Apennines. In addition to this, despite the occurrence of large earthquakes in Calabria, Westaway (1992) suggests that aseismic deformation plays an important role in Calabria being characterised by a low extension velocity of $\sim 0.5-1 \mathrm{~mm} / \mathrm{yr}$.

The first part of the paper is dedicated to data analyses used for the strain computation, that are the seismic moment of historical earthquakes, kinematics of faults, and associated fault length of the Apennines and Calabrian arc earthquakes. After having described the spatial distribution of horizontal principal strain rate axes, I discuss the seismotectonic implication from a kinematic view point.

\section{Data analyses}

\subsection{Moment tensor of historical earthquakes}

Scalar seismic moment $\left(M_{o}\right)$ is the most suitable seismological parameter for the quantification of source strength (Aki, 1967). This parameter can be easily computed by means of the conventional seismological procedures only for those earthquakes which have been instrumentally recorded. Hanks et al. (1975) proposed a method to estimate $M_{o}$ when macroseismic intensity data are available but instrumental data are not. The method is based on the observation that the area extent $A(I)$ of the region in which the earthquake is felt with intensity $I$ is an increasing function of the earthquake size. Hanks et al. (1975) used 16 earthquakes of the Southern California region whose seismic moments were known from instrumental estimates to establish a relationship between the logarithm $M_{o}$ and the logarithm $\mathrm{A}(\mathrm{VI})$, where $\mathrm{A}(\mathrm{VI})$ is the area enclosing the Modified Mercalli intensity MMI = VI. Hanks and Johnston (1992) extended this method to Eastern North America and Western U.S. earthquakes for a comparative study, using 
III < MMI < VIII. A further development of such method, proposed by Johnston (1996), were used by Gasperini and Ferrari (1997) to estimate the scalar seismic moment of large historical earthquakes contained in the Italian seismic catalogue (Boschi et al., 1997).

I have selected all the earthquakes larger than $1.2 \cdot 10^{25}$ dyne $\cdot \mathrm{cm}$, corresponding to a moment magnitude of 6.0 . Each earthquake used in this work has been associated with a kinematics deduced from seismological or geodetic observation, geomorphological data or to known active structures, and the driving considerations are based on the experience gained in recent years on the mode of crustal deformation of the Italian peninsula. In the Northern Apennines both Gubbio 1984 (Haessler et al., 1988), and Umbria-Marche 1997 (Amato et al., 1998) earthquakes suggest that seismic deformation is accommodated by low angle normal faults $\left(35^{\circ}-45^{\circ}\right)$ striking NW-SE and dipping towards SW bordering the intramountain basins filled by Quaternary sediments. Geological and paleoseismological studies (Blumetti, 1995; Galadini et al., 1997) are consistent with such mechanism, allowing many of the earthquakes to be associated with normal faults that border the Quaternary basins. Similarly, in Southern Apennines normal faulting is the typical mechanism involved in the deformation as testified by the Avezzano 1915 and the Irpinia 1980 earthquakes. Here, faults are steeper than in the Northern Apennines, dipping to an angle of about $60^{\circ}$. The fault parameters associated to historical earthquakes used in this work are taken from geomorphological, paleoseismological, and macroseismic evidence reported for these faults (Figliuolo, 1988; Valensise et al., 1993; Cucci et al., 1996; Pantosti et al., 1996; Benedetti et al., 1997).

In the Calabrian arc, only the fault responsible for Messina 1908 large earthquake has seismometric and geodetic constraints that allow the geometry of the activated structure to be determined. Such mechanism involves a low angle normal fault striking NNE and dipping towards ESE (Capuano et al., 1988; Valensise et al., 1993). The same style of deformation has been associated with the earthquakes which occurred on the western coasts of the Calabrian arc in agreement with morphological and macroseismic data (Valensise et al., 1993; D’Ajello Caracciolo, 1996). In addition, the elongation of the macroseismic area extent of four Calabrian earthquakes (1659; 1783/03/28; 1638, and 1836) suggests that seismic deformation is also associated to faults striking in $\sim$ EW direction. I have speculatively assumed that these four earthquakes occurred on the normal faults bordering the EW Quaternary graben of Calabria. This hypothesis is based on the evidence of a secondary direction of extension perpendicular to the principal WNW one, deduced from extensive studies on Quaternary faulting (Moussat et al., 1986) and on the direction of the horizontal minimum stress derived from borehole breakouts of 4 wells on the Ionian side of the Calabrian arc (Montone et al., 1997).

\subsection{Length of faults deduced from constant strain drop}

The strain produced by the dislocation on a rectangular fault is, intuitively, proportional to the average slip $(D)$ and to the length $(L)$ or width $(W)$ of the fault. Seismic static theory tells that the ratio between $D$ and $L$ or $W$, the strain drop, is related to the stress drop by the Hook law $\left(\Delta \sigma=C \mu k_{1}\right)$, where $C$ is an adimensional constant depending on fault geometry and $k_{1}$ is the strain drop. Constant stress drop implies constant strain drop for constant rigidity $\mu$. Stress drop is highly dependent on the tectonic regime, varying by one or two orders of magnitude from compressional to extensional regimes and from intraplate to interplate earthquakes. In homogeneous seismotectonic regions constant stress drop is generally observed, that is the ordinary explanation of the linearity between logarithm of scalar seismic moment and logarithm of fault area (Kanamori and Anderson, 1975). The similarity condition between stress drop and strain drop is well satisfied for large earthquakes. Constant strain drop is world-wide verified and assumes a roughly constant value of $3 \div 8 \cdot 10^{-5}$. 
From the definition of scalar seismic moment, fault length $(L)$ can be derived as follow:

$$
L=\sqrt{\frac{M_{o}}{\mu W k_{1}}}
$$

$W$ can be determined from the thickness of the seismogenic layer $\left(H_{o}\right)$ and the $\operatorname{dip}(\delta)$ of the fault $\left(W=\frac{H_{o}}{\sin (\delta)}\right)$ and $\mu$ is assumed hereafter to be $3 \cdot 10^{11}$ dyne $\cdot \mathrm{cm}^{-2}$.

The limit of such an empirical method is the large uncertainties related to each parameter of relation (2.1). Nevertheless, for tectonic purposes it is a valid independent estimate of fault lengths, to be compared with geological and paleoseismological results when available, because the Apennines are a homogeneous extensional stress regime and stress drop is roughly constant (Rovelli et al., 1988), several seismic local networks provide a good assessment of the seismogenic layer, and scalar seismic moment of historical earthquakes is available (Boschi et al., 1997). The motivation for this approach derives from the observation that little is known about the geometric characteristics of the seismogenic faults responsible for the large earthquakes of the past due to the lack of clear surface expression, the presence of blind or hidden faults and to the growing evidence that the young age of the extensional regime has not yet overprinted the older morphology.

I have analysed the only four normal faulting earthquakes which occurred in the Apennine region for which there are estimates of slip $(D)$ and length $(L)$ (Valensise, 1988; Ward and Valensise, 1989; Pantosti and Valensise, 1993; Hunstad et al., 1998) to verify that strain drop assumes an almost constant value for normal faulting earthquakes in Italy. The estimate of $D$ and $L$ are based on levelling measurements for two events (namely Avezzano 1915, and Messina 1908), for the Irpinia 1980 event I refer to geological estimates (Pantosti and Valensise, 1993) and for the recent UmbriaMarche earthquake, the estimate of slip and length is based on geodetic results (Hunstad et al., 1998).

Avezzano 1915 is a pure normal faulting earthquakes of magnitude 6.7 (Ward and Valensise, 1989). The slip $D$ and length $L$ were derived from the results in Ward and Valensise (1989) that analysed the repeated levelling surveys carried out before and after the earthquake. The direct model that fits the coseismic deformation is a $24 \mathrm{~km}$ long fault with an average slip of $0.8 \mathrm{~m}$. The strain drop assumes a value of $3.3 \cdot 10^{-5}$. Messina 1908 earthquake is a pure normal fault event of magnitude 7.0 (Valensise, 1988). The repeated measurements of levelling lines provided a dislocation model with average slip of $1.4 \mathrm{~m}$ for a $45 \mathrm{~km}$ long fault and consequently a strain drop of $3.1 \cdot 10^{-5}$. For the Irpinia earthquake I refer to the paper of Pantosti and Valensise (1993) that reports a summary of the main source parameters from field observations. An average slip of $1.1 \mathrm{~m}$ for a $34 \mathrm{~km}$ long fault is derived from their results corresponding to a strain drop of $3.2 \cdot 10^{-5}$. The slip and length of the $1997 \mathrm{Um}$ bria-Marche normal faulting earthquake are well constrained by GPS data (Hunstad et al., 1998) revealing $33 \mathrm{~cm}$ of slip for $12 \mathrm{~km}$ of fault. The strain drop is $2.8 \cdot 10^{-5}$. Summarising the observations, it is reasonable to consider strain drop a roughly constant characteristic feature for normal fault earthquakes of the Apenninic system (fig. 2). I have used an average value of strain drop equal to $3 \cdot 10^{-5}$ to calculate the fault length of the historical earth-

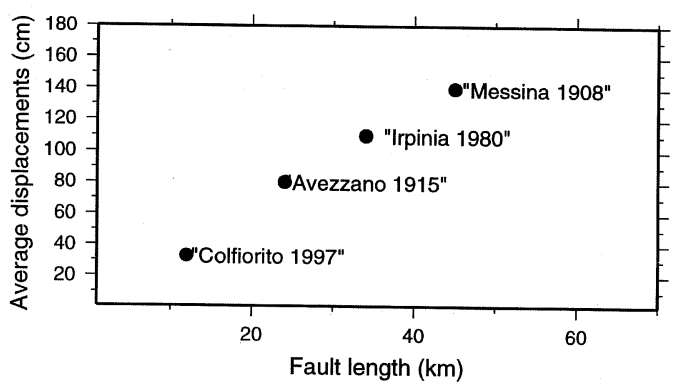

Fig. 2. Fault length versus average displacement for the four earthquakes discussed in the text. 
quakes, that means $30 \mathrm{~cm}$ of average slip for every ten kilometers of fault length corresponding to a static stress drop equal to $\sim 10$ bar, although four cases are not enough to derive such a general behaviour.

The depth of the seismogenic layer was deduced from detailed images of the crustal seis- micity derived from temporary and permanent seismic local networks that have been in operation during the last twenty years in Italy. I am confident that using a depth of $12 \mathrm{~km}$ of the seismogenic layer I commit a negligible error in determining $W$. The experience of the Irpinia, Gubbio, and other normal faulting earth-
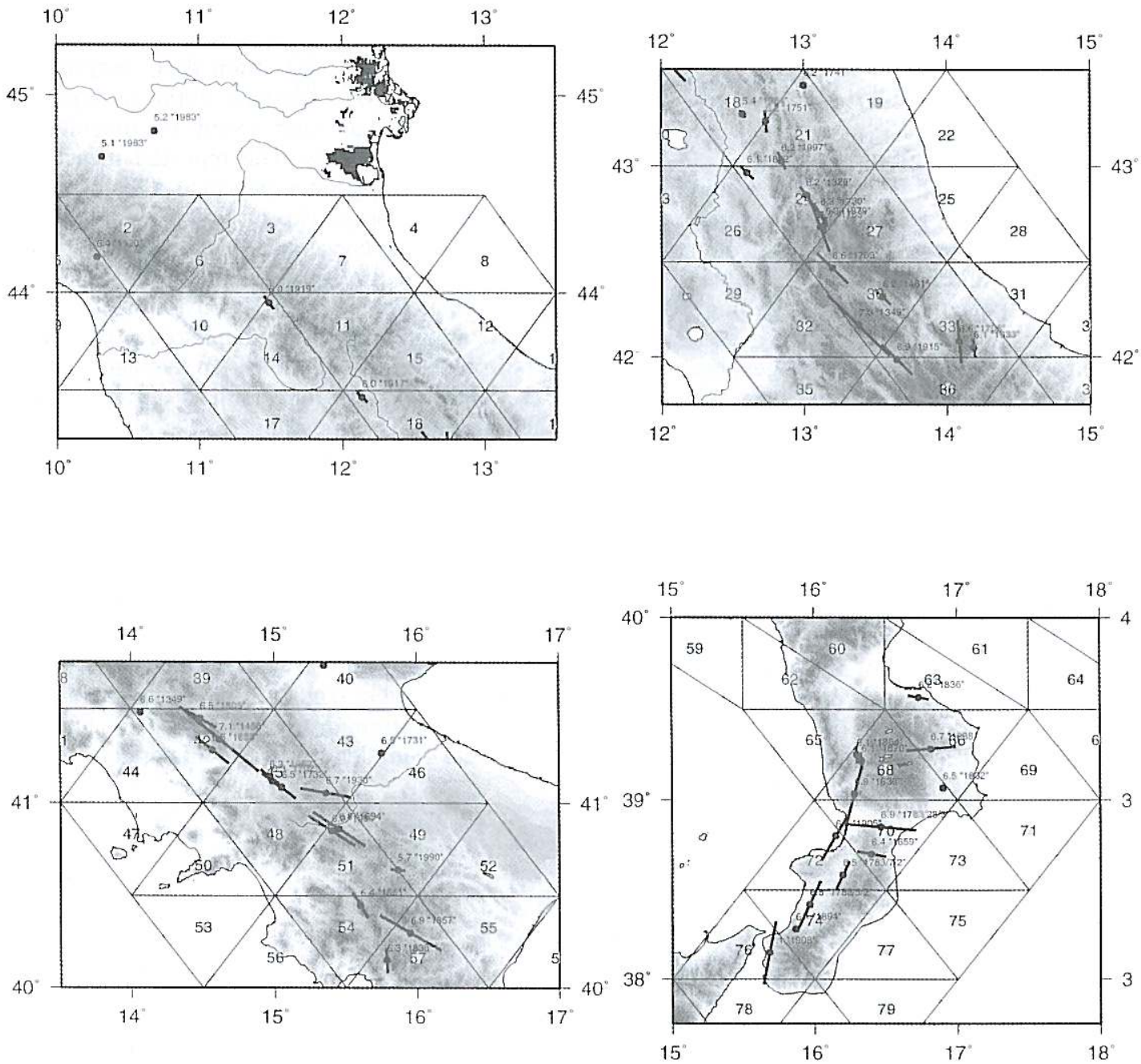

Fig. 3. Fault length derived from constant strain drop. Epicentres are from the seismic catalogue (Boschi et al., 1997). Also shown are the magnitude and dates of earthquakes and the triangular mesh used to calculate seismic strain rate. 
quakes in the Apennines suggest that the entire seismogenic layer breaks only for those earthquake whose magnitude exceeds 6.0. For smaller earthquakes, that are few in the data set, I used a linear decrease of $W$ with magnitude.

The application of relation (2.1) to historical earthquakes provides the fault lengths portrayed in fig. 3.

\section{Spatial distribution of principal strain rate axes}

The cumulative scalar seismic moment for the earthquakes used in this study is $4.88 \cdot 10^{27}$ dyne $\cdot \mathrm{cm}$. Only six per cent of it is released in the Northern Apennines $\left(0.3 \cdot 10^{27}\right.$ dyne $\left.\cdot \mathrm{cm}\right)$ by faults that are generally $10-12 \mathrm{~km}$ long (except for the 1703 Norcia earthquake), while $56 \%$ is released in the Southern Apennines $\left(2.73 \cdot 10^{27}\right)$ by faults that can be even longer than $40 \mathrm{~km}$. The Calabrian arc contributes $38 \%$ of the total $\left(1.84 \cdot 10^{27}\right.$ dyne $\left.\cdot \mathrm{cm}\right)$. This first result shows that the seismic release is strongly different along Italy both in magnitude and in the dimension of faults involved in the active deformation.

Once the data set was built, the next step was to evaluate the best regular triangular mesh within which to calculate the principal strain rate axes. Of course there are several possible grids that can be drawn but I sought for a dimension of triangles comparable with the length of faults to ensure the continuity of strain between adjacent triangles. Figure 3 shows the one I chose.

Since only a large time window, whose length is comparable with the recurrence time of regional seismic release, allows a meaningful long term deformation pattern to be derived in a low seismic strain rate region, as Italy seems to be, I am forced to make the assumptions on faulting mechanism for historical earthquakes and to deal with the consequent uncertainties. One way to treat this problem is to assess formal uncertainties in the data and to derive interval of confidence. The cost I have to pay, is that I can only discuss the first order features and lose the small scale characteristics of the strain field. I let strike, dip and rake of inferred faults to vary of \pm 10 degrees from the assumed values, and length of faults is calculated with constant strain drop ranging between 2.8 and $3.2 \cdot 10^{-5}$ and scalar seismic moments of \pm 0.1 of its logarithm values. These uncertainties are reasonable and larger variations are not expected. Considering such uncertainties, the direction and length of the horizontal principal strain rate axes ranges between $\pm 15^{\circ}$ and $30 \%$ of their average values, respectively.

Figure 4 shows the distribution of horizontal principal seismic strain rate axes along the Italian peninsula using England and Molnar's approach (1997). Black bars indicate extensional strains and the length is proportional to magnitude of strain. In the Northern Apennines extensional strain is everywhere smaller than $1 \cdot 10^{-15} \mathrm{~s}^{-1}$, only Norcia region (triangle 24) is characterised by a significant value of seismic strain mainly due to the occurrence of the 1703 earthquake. The direction of extension is NESW and, taking into account the dimension of the whole Northern Apenninic arc $(200 \mathrm{~km})$ and rotating the reference frame so that one axis is aligned with the chain, the observed strain rate results in an average extension rate of $0.3 \mathrm{~mm} / \mathrm{yr}$.

Values of strain rates up to $2 \cdot 10^{-15} \mathrm{~s}^{-1}$ are observed in the Southern Apennines, corresponding to an average extension rate in NESW direction, calculated considering a length of $400 \mathrm{~km}$ for the Southern Apennines, of $1.6 \mathrm{~mm} / \mathrm{yr}$. Figure 4 shows that horizontal strain is homogeneously distributed along the Southern Apennines, suggesting that large differences in the extension rate are not expected. As introduced before, Westaway (1992) suggested a local maximum of the extension rate up to $5 \mathrm{~mm} / \mathrm{yr}$ in the central part of the Southern Apennines tapering to almost zero at the edge of the region. The differences in my estimate with regards to Westaway (1992) depend on both the data and the method. I have used a larger data set, including earthquakes of the XIV and XV centuries that greatly contributed to average the strain along the Apennines. 


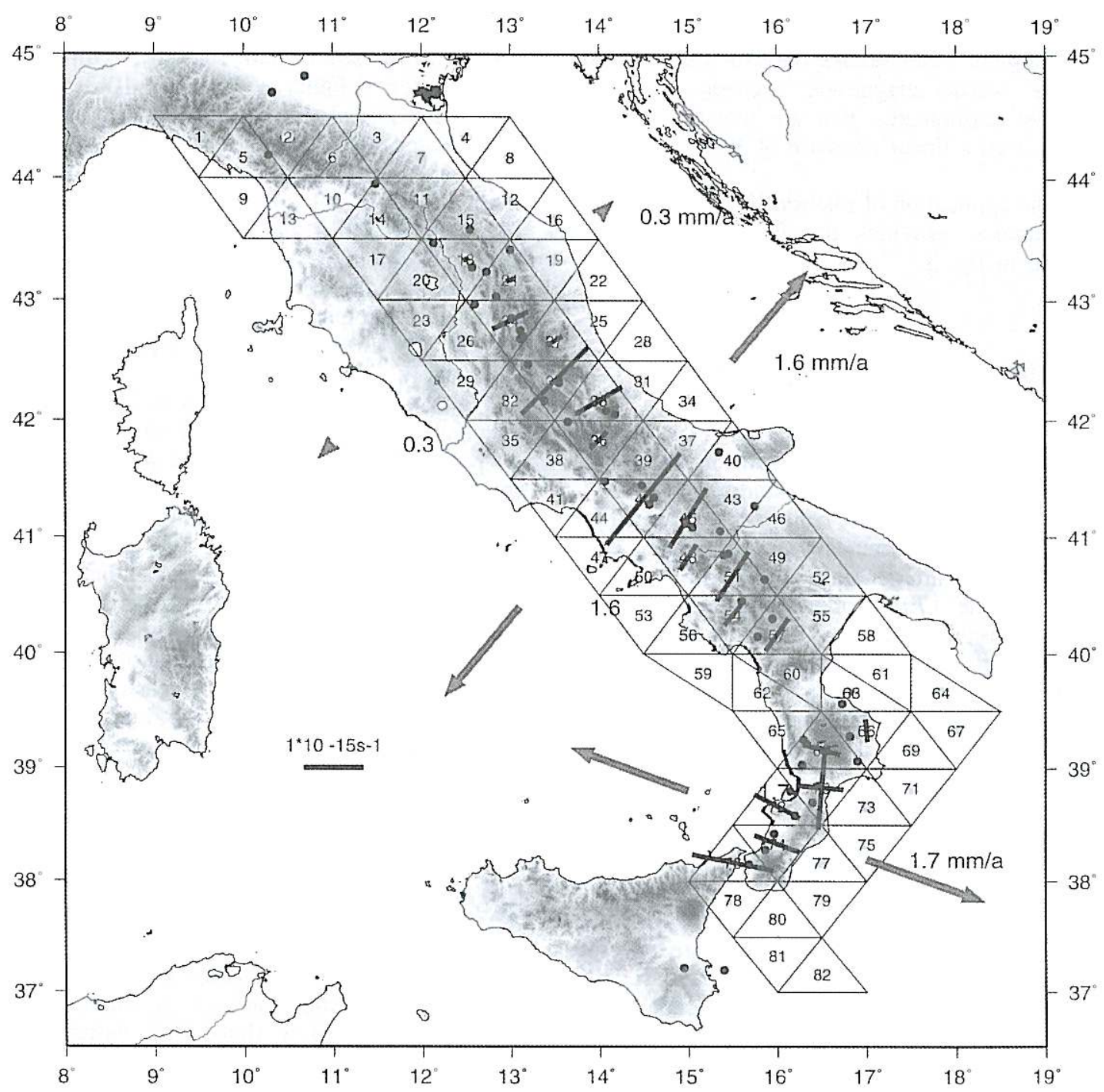

Fig. 4. Horizontal principal strain rate axes from historical seismicity since 1349 . Black bars indicate extensional strain. The extension rate perpendicular to the chain is $1.6 \mathrm{~mm} / \mathrm{yr}$ in Southern Apennines and $1.7 \mathrm{~mm} / \mathrm{yr}$ in Calabria. It is $\sim 0.3 \mathrm{~mm} / \mathrm{yr}$ in the Northern Apennines.

One of the main features, that still remains also considering the uncertainties, is the widely different strain and extension rate between the Southern Apennines with respect to the northern Apennines. Such difference cannot, in principle, be referred to tectonic causes alone, and independent strain data are needed. This is because if a different percentage of seismic strain with respect to total strain is released in the two arcs, then rheological causes can contribute to explain such differences. The evidence in favour of this hypothesis is the depth 
distribution of earthquakes. In the Northern Apennines the recent earthquakes of Gubbio 1984, Umbria-Marche 1997, and Norcia 1979 show that the seismogenic layer might be restricted to the first $8-10 \mathrm{~km}$ of the crust, while the Irpinia 1980 and Potenza 1990 earthquakes enlighten a deeper seismogenic layer for the Southern Apennines, probably deeper than $10 \mathrm{~km}$. A better definition of earthquake depth distribution could help to elucidate why different maximum magnitude and fault length are observed along the Apennines. Moreover, temperature estimates at $3 \mathrm{~km}$ depth are notably higher in the Northern Apenninic arc than in the Southern Apennines (100-110 degrees versus 60-70; Mongelli et al., 1989), spurring further investigation of the crustal thermal state. Conversely, much geophysical evidence, like tomographic images of the upper mantle (Amato et al., 1993), the intermediate depth earthquake distribution (Selvaggi and Amato, 1992), and seismic anisotropy (Margheriti et al., 1996), states that the Northern and Southern Apennines are currently undergoing different geodynamic processes. How these are related to crustal seismic release of the Apennines may be better resolved by models concerned with the forces involved in the deformation.

The Calabrian arc is characterised by an $\sim$ WNW-ESE extensional strain rate of the order of $1 \cdot 10^{-15} \mathrm{~s}^{-1}$ involving a velocity of extension of $1.7 \mathrm{~mm} / \mathrm{yr}$ averaged over the 200 $\mathrm{km}$ of length of the arc. The introduction of the $\sim$ EW trending earthquakes produces significant strain that results in longitudinal dilatation of the arc.

The occurrence of normal faulting earthquakes on $\sim \mathrm{EW}$ striking faults is a strong assumption of this work motivated by structural observations (Moussat et al., 1986), fault plane solutions of recent moderate earthquakes (Frepoli and Amato, 1998), and borehole breakouts (Montone et al., 1997), and finds its explanation in the active migration of the Calabrian arc. How far it is possible to stress this hypothesis depends on the information that will come from the still missing geodetic results.

\section{Conclusions}

In this paper I have shown that a kinematic description derived from a long time interval of seismicity is useful to treat many open questions related to the seismotectonics of the Apennines, although new ones have been opened. Also considering data uncertainty, it does not dramatically affect the seismic strain field. Results show that deformation is achieved differently along the Apennines. In the Northern Apennines faults are generally 10 to $12 \mathrm{~km}$ long and the strain rate is low. On the contrary, both the Southern Apennines and Calabrian arc are characterised by faults up to $40 \mathrm{~km}$ of length, strain greater than $1 \cdot 10^{-15} \mathrm{~s}^{-1}$, and extension rate of the order of $1.6 \mathrm{~mm} / \mathrm{yr}$.

\section{Acknowledgements}

I thank the Executive Editor C. Gasparini for the opportunity he gave me to write this paper and E. Boschi for continuous encouragement. P. Gasperini provided the scalar seismic moment of the historical earthquakes and many parts of the paper were carried out with the helpful suggestions of B. Castello, A. Amato. I also thank I. Hunstad for reading and improving the manuscript and A. Basili for constructive review.

This work has been partially founded by ASI-ARS contract 1997.

\section{REFERENCES}

AKI, K. (1967): Scaling law of seismic spectrum, J. Geophys. Res., 72, 1217-1231.

Amato, A., B. Alessandrini, G.B. Cimini, A. Frepoli and G. SelvagGi (1993): Active and remnant subducted slabs beneath Italy: evidence from seismic tomography and seismicity, Ann. Geofis., 36 (2), 201-214.

Amato, A., R. Azzara, C. Chiarabba, G.B. Cimini, M. Cocco, M. Di Bona, L. Margheriti, S. Mazza, F. Mele, G. Selvaggi, A. Basili, E. Boschi, F. Courboulex, A. Deschamps, S. GafFet, G. Bittarelli, L. Chiaraluce, D. Piccinini and M. RiPePe (1998): The Colfiorito, Umbria-Marche earthquake sequence in Central Italy (Sep.-Nov., 1997): a first look to mainshocks and aftershocks, Geophys. Res. Lett., 25 (15), 2861-2864. 
ANDERSON, H. and J. JACKSON (1987): Active tectonics of the Adriatic region, Geophys. J. R. Astron. Soc., 91, 937-987.

Benedetti, L., P. TAPPonier, G.K. King and L. PicCardi (1997): Surface faulting of the 1857 Italian earthquake? Eos, Trans. Am. Geophys. Un., 635.

BlumetTI, A.M. (1995): Neotectonic investigations and evidence of paleoseismicity in the epicentral area of the January-February 1703, Central Italy, earthquakes, in Prospectives in Paleoseismology, edited by L. SERVA and D.B. Slemmons, Assoc. Eng. Geol. Spec. Publ., 6 , 83-100.

Boschi, E., E. Guidoboni, G. Ferrari, G. VAlensise and P. GASPERINI (Editors) (1997): Catalogo dei Forti Terremoti in Italia dal 461 a.C. al 1990 (ING, Roma SGA, Bologna), pp. 644.

Capuano, P., G. De Natale, P. Gasparini, F. Pingue and R. SCARPA (1988): A model for the 1908 Messina Straits (Italy) earthquake by inversion of levelling data, Bull. Seism. Soc. Am., 78, 1930-1947.

Cocco, M., G. Selvaggi, A. Basili and M. Di Bona (1993): Recent seismic activity and earthquake occurrence in Southern Italy, in Recent Evolution and Seismicity of the Mediterranean Region, edited by E. Boschi, E. Mantovani and A. Morelli, 295-312

Cucci, L., G. D'Addezio, G. VAlensise and P. BurraTO (1996): Investigating seismogenic faults in Central and Southern Apennines (Italy): modelling of faultrelated landscape features, Ann. Geofis., 39 (3), 603-618.

D'AJello CARACCIOlO, F. (1996): Strutture sismogenetiche principali dell'Appennino Centrale e Meridionale e distribuzione di momentto sismico nel decennio '85-'94, Tesi di Laurea, Università di Roma (in Italian).

Deschamps, A., G. IANNACCONE and R. SCARPa (1984): The Umbrian earthquake (Italy) of 19 September 1979, Ann. Geophysicae, 2, 29-36.

ENGLAND, P. and P. MolNAR (1997): The field of crustal velocity in Asia calculated from Quaternary rates of slip on faults, Geophys. J. Int., 130, 551-582.

Figliuolo, B. (1988): Il Terremoto del 1456, Osservatorio Vesuviano e Istituto Italiano per gli Studi Filosofici (Ed. Studi Storici Meridionali), vol. 1 and 2.

Frepoli, A. and A. AMATO (1998): Extension in Southern Apennines and compression in Sicily from fault plane solutions, Geophys. J. Int. (submitted).

Galadini, F., P. Messina, R. BAsili and C. Bosi (1997): Faglie attive nell'Appennino Centro-Meridionale, Gruppo Nazionale per la Difesa dai Terremoti, General Assembly, 41-44 (extended abstract).

GASPERINI, P. and G. FERRARI (1997): Stima dei parametri sintetici: nuove elaborazioni, in: Catalogo dei Forti Terremoti in Italia dal 461 a.C. al 1990, edited by E. Boschi. E. Guidoboni, G. Ferrari, G. Valensise and P. GASPARINI (ING, Roma - SGA, Bologna), pp. 644

Haessler, H., R. Gaulon, L. Rivera, R. Console, M. Frogneux, C. Gasparini, L. Martel, G. Patau, M. Siciliano and A. Cisternas (1988): The Perugia (Italy) earthquake of 29/04/'84: a microearthquake survey, Bull. Seism. Soc. Am., 78, 1948-1964.
HAINES, A.J. (1982): Calculating velocity fields across plate boundaries from observed shear rates, Geophys. J. R. Astron. Soc., 68, 203-209.

HANKs, T.C. and A.C. JoHnston (1992): Common features of the excitation and propagation of strong ground motion for North American earthquakes, Bull. Seism. Soc. Am., 82, 1-23.

HaNkS, T.C., J.A. HiLEMAN and W. Thatcher (1975): Seismic moment of the larger earthquakes of the Southern California region, Geol. Soc. Am. Bull., 86, 1131-1139.

Hunstad, I., M. Anzidei, M. Cocco, P. Baldi, A. Pesci and A. Galvani (1998): Modelling coseismic deformation during the 1997 Umbria-Marche earthquake (Central Italy), Geophys. J. Int. (submitted).

KANAMORI, H. and D.L. ANDERSON (1975): Theoretical basis of some empirical relations in seismology, Bull. Seism. Soc. Am., 65 (5), 1073-1095.

Kostrov, V.V. (1974): Seismic moment and energy of earthquakes, and seismic flow of rock, Izv. Acad. Sci. USSR Phys. Solid Earth, 1, 23-44.

JACKSON, J. and D. MCKENZIE (1988): The relationship between plate motion and seismic moment tensor, and the rates of active deformation in the Mediterranean and Middle East, Geophys. J., 93, 45-73.

JACKSON, J., A.J. HAINES and W. HolT (1992): The horizontal velocity field in the deforming Aegean Sea region determined from the moment tensors of earthquakes, J. Geophys. Res, 97 (B12), 17657-17684.

JoHNSTON, A.C. (1996): Seismic moment assessment of earthquakes in stable continental regions - II, Historical seismicity, Geophys. J. Int., 125, 639-678.

Margheriti, L., C. Nostro, M. Cocco and A. Amato (1996): Seismic anisotropy beneath the Northern Apennines (Italy) and its tectonic implications, Geophys. Res. Lett., 23 (20), 2721-2724.

Mongelli, F., G. Zito, N. Ciaranfi and P. Pieri (1989): Interpretation of heat flow density of the Apennine chain, Italy, Tectonophysics, 164, 267-280.

Montone, P., A. Amato, A. Frepoli, M.T. MariucCI and M. CESARo (1997): Crustal stress regime in Italy, Ann. Geofis., 40 (3), 741-757.

Moussat, E., J. Angelier, G. Mascle and J.P. Rehault (1986): L'ouverture de la Mer Tyrrhénienne et la tectonique de faille néogène quaternaire en Calabre, G. Geol., 481, 63-75 (in French).

Pantosti, D. and G. VAlENSISE (1993): Source geometry and long-term behavior of the 1980, Irpinia earthquake fault based on field geologic observations, Ann. Geofis., 36 (1), 41-49.

Pantosti, D., G. D'Addezio and F.R. Cinti (1996): Palaeoseismicity of the Ovindoli-Pezza fault, Central Apennines, Italy: a history including as large, previously unrecorded earthquake in Middle Ages (8601300 A.D.), J. Geophys. Res., 101 (B3), 5937-5959.

Pondrelli, S., A. Morelli and E. Boschi (1995): Seismic deformation in the Mediterranean area estimated by moment tensor summation, Geophys. J. Int., 122, 938-952.

Rovelli, A., O. Bonamassa, M. Cocco, M. Di Bona and S. MAZZA (1988): Scaling laws and spectral parameters of the ground motion in active extensional areas in Italy, Bull. Seism. Soc. Am., 78, 530-560. 
Selvaggi, G. and A. Amato (1992): Subcrustal earthquakes in the Northern Apennines (Italy): evidence for a still active subduction?, Geophys. Res. Lett., 19 (21), 2127-2130.

Selvaggi, G., B. Castello and R. Azzara (1997): Spatial distribution of scalar seismic moment release in Italy (1983-1996): seismotectonic implications for the Apennines, Ann. Geofis., 40 (6), 1565-1578.

VALENSISE, G. (1988): Low angle normal faulting during the 1908, Messina, earthquake revealed by geodetic data analysis, Eos, Trans. Am. Geophys. Un., 69, 1433.

Valensise, G., D. Pantosti, G. D’Addezio, F.R. Cinti and L. CUCCI (1993): L'identificazione e la caratterizzazione di faglie sismogenetiche nell'Appennino Cen-
tro-Meridionale e nell'arco Calabro: nuovi risultati e ipotesi interpretative, in Atti XII Convegno GNGTS, Roma 1993, 331-342.

WARD, S.N. and G. VALENSISE (1989): Fault parameters and slip distribution of the 1915, Avezzano, Italy earthquake derived from geodetic observations, Bull. Seism. Soc. Am., 79, 690-710.

WESTAWAY, R. (1992): Seismic moment summation for historical earthquakes in Italy: tectonic implications, $J$. Geophys. Res., 97 (11), 15437-15464

(received April 23, 1998; accepted June 25, 1998) 